\title{
Remodeling and Fibrosis in Chronic Eosinophil Inflammation
}

\author{
Seema S. Aceves \\ Division of Allergy, Immunology, Department of Pediatrics and Medicine, University of California, San Diego, \\ Rady Children's Hospital, San Diego, Calif., USA
}

\section{Key Words}

Remodeling · Fibrosis · Eosinophils · Eosinophilic esophagitis · Natural history

\begin{abstract}
Chronic eosinophilic inflammation has been associated with tissue remodeling in a number of disease states including the hypereosinophilic syndrome (HES), asthma, and, more recently, eosinophilic esophagitis (EoE). Remodeling occurs in the epithelial and subepithelial esophageal tissue, and includes basal zone hyperplasia, epithelial mesenchymal transition, fibrosis, angiogenesis, and smooth muscle hypertrophy/hyperplasia. Previously, research on the clinical impacts of tissue remodeling has been limited by a paucity of human tissue. However, in EoE, recurrent biopsies are required for diagnosis and management. As such, investigators are able to study the associations between tissue changes and clinical disease features. A number of profibrotic and proangiogenic factors are elevated in EoE, including TGF- $\beta 1, C C L-18$, FGF-9, VEGF, and VCAM-1. Both eosinophils and mast cells produce a number of these factors. TGF- $\beta 1$ appears to be a master regulator of end-organ dysfunction in EoE and can cause esophageal epithelial mesenchymal transition, fibrosis, and smooth muscle contraction. The requirement for eosinophils, the eosinophilopoietic interleukin, IL-5, and the canonical TGF- $\beta 1$ signaling pathway for EoE-associated fibrosis, has been invoked using gene-deficient mice. The clin-
\end{abstract}

ical consequences of eosinophil-associated tissue fibrosis can be devastating, such as endomyocardial fibrosis and heart failure in HES. In EoE, tissue remodeling appears to be the mechanism for multiple cardinal disease complications including esophageal rigidity, strictures, narrowing, and food impactions, as well as the clinical hallmark of dysphagia. Therapies that may be able to reduce or reverse EoEassociated remodeling include topical corticosteroids, antiIL-5, and food antigen avoidance.

(c) 2014 S. Karger AG, Basel

\section{Introduction}

The notion of eosinophil-associated tissue remodeling has its nascence in the hypereosinophilic syndrome (HES) and asthma [1-3]. In both diseases, eosinophilic tissue infiltration causes significant morbidity and, in the case of HES, mortality $[1,4]$. Endomyocardial fibrosis can lead to heart failure in HES. Airway remodeling leads to irreversible airway obstruction in asthma [1,2]. More recently, eosinophilic esophagitis (EoE) has been added to the list of eosinophil-associated atopic disorders in which remodeling plays an important role in both symptoms and disease complications [5-8].

The pivotal ways in which EoE has and will continue to shift our understanding of remodeling is in the context of disease natural history as well as in our understanding

\section{KARGER}

E-Mail karger@karger.com

www.karger.com/ddi
(C) 2014 S. Karger AG, Base

0257-2753/14/0322-0015\$39.50/0
Seema S. Aceves, MD, $\mathrm{PhD}$

Division of Allergy, Immunology, Department of Pediatrics and Medicine University of California, San Diego

Rady Children's Hospital, San Diego, CA (USA)

E-Mail saceves@ucsd.edu 
of the clinical consequences and associations of tissue changes in the pediatric population. This is largely due to the fact that, unlike other eosinophilic disorders, EoE requires repeated tissue sampling [7]. EoE cannot be diagnosed or appropriately followed for therapeutic response without repeated tissue procurement [7]. In the process of assessing the severity of eosinophil inflammation, investigators can begin to also research mechanisms of remodeling.

Features of esophageal remodeling in EoE include epithelial changes of basal zone hyperplasia due to active cellular proliferation of the basal cells that provide a constant renewal source for the epithelium, increased extension of the lamina propria (LP) projections of vascular papillae, dilated intercellular spaces that likely reflect edema due to angiogenesis and vascular leak, and epithelial mesenchymal transformation. Subepithelial tissue remodeling includes LP fibrosis as well as smooth muscle hypertrophy and hyperplasia [9-14]. It is likely that esophageal remodeling is the molecular scaffold for the cardinal clinical symptoms of dysphagia and the major EoE complications of food impactions, strictures, and esophageal dysmotility. This review will summarize our current understanding of esophageal remodeling in EoE from its molecular mechanisms to its clinical outputs and reversibility.

\section{Eosinophil-Associated Tissue Remodeling in EoE}

\section{Molecular Pathogenesis of Remodeling in EoE}

The numbers of studies that have been published on the topic of tissue remodeling in EoE underscore the significant and growing research interest on this topic $[5,12$, 15-19]. Multiple strides have been made in understanding the pathogenesis of EoE-associated remodeling and has been aided by the use of animal models. These models are helpful especially due to a paucity of deeply sampled human esophageal tissue during biopsy. In the case of asthma, Th2-associated interleukins as well as profibrotic and proremodeling agents made by eosinophils are thought to cause a progressive loss of airway function leading to irreversible obstruction [2]. In the HES, eosinophil products, such as major basic protein (MBP), have shown extracellular deposition and likely mediate the damage that leads to endomyocardial fibrosis.

Tissue remodeling in EoE and other eosinophil-associated diseases can be considered to occur due to repeated molecular attempts at wound healing. Since the inflammatory insult is chronic, the cumulative result of ongoing healing is a robust production of fibrosis and angiogenesis as well as hypertrophy and hyperplasia of structural cells such as the epithelium and smooth muscle. Indeed, these cells themselves can subsequently contribute to the perpetuation of both inflammation and remodeling. Although remodeling and fibrosis is initially coupled with inflammation, it seems that in long-standing remodeling disease, such as that seen in adult EoE subjects, inflammation and remodeling can, intriguingly, become uncoupled $[6,10,16,20-22]$. As such, a process of healing and fibrosis becomes dysfunctional and, perhaps, self-perpetuating.

The requirement for repeated tissue procurement in the diagnosis and management of EoE has been pivotal for investigations into the molecular events involved in esophageal remodeling. The study of other human eosinophilic diseases is hampered by the lack of repeated tissue analysis and a paucity of research that can study the occurrence and pathogenesis of remodeling in young children. However, EoE is often diagnosed in young children and our studies demonstrate that children as young as 2 years of age can have fibrosis and significant TGF- $\beta 1$ production $[13,20,23]$.

\section{Epithelial Remodeling}

In the epithelium, eosinophils can potentially modulate epithelial basal zone hyperplasia. Eosinophil products such as MBP can cause proliferation of a cultured cell line of esophageal epithelial cells. By altering the function of the calcium-sensing channel CaSR, MBP increases FGF-9 levels and epithelial cell proliferation [24]. Indeed, the numbers of eosinophils can correlate with the degree of basal zone hyperplasia in EoE biopsies.

In addition, eosinophil products such as TGF- $\beta 1$ can drive epithelial mesenchymal transformation in EoE. The amount of MBP, the numbers of eosinophils and TGF$\beta 1$-positive cells, and the presence of fibrosis all correlate significantly with markers of epithelial mesenchymal transformation such as vimentin [19]. Treatment of an esophageal epithelial cell line with TGF- $\beta 1$ causes increased vimentin and fibronectin transcription while decreasing cytokeratins [19].

\section{LP Remodeling}

The bulk of remodeling changes occur in the subepithelial compartments [5]. Definitive evidence for eosinophil-mediated fibrosis comes from murine model systems. Mice that lack eosinophils due to the absence of IL-5 or due to a mutation that blocks Gata- 1 from binding its own promoter are protected from experimental pol- 
len-induced esophageal fibrosis $[12,18]$. In adults, treatment with a humanized anti-IL-5 antibody decreases the expression of epithelial TGF- $\beta 1$ and basement reticular membrane tenascin $C$ [25].

IL-5, IL-13, and TGF- $\beta 1$ are master regulators of EoE $[12,15,17,18,26-28]$. Both IL- 13 and TGF- $\beta 1$ can induce other profibrotic agents such as periostin in the LP [29]. Periostin itself is secreted by esophageal fibroblasts in the presence of IL-13 and causes chemoattraction of eosinophils along with eotaxin-3 [29]. In murine models, treatment with an anti-IL-13 antibody protects from experimental EoE, and intratracheal instillation of IL-13 induces EoE [30]. Clara cell overexpression of IL-13 has significant consequences on esophageal function $[17,28$, 30]. IL-13 overexpression is sufficient for the accumulation of esophageal collagen and esophageal thickness with edema, and these effects are diminished when the IL-13 receptor is absent [28]. In addition, IL-13 overexpression has impressive effects on murine EoE with weight loss and esophageal strictures [17].

Mast cell numbers are elevated in the epithelium and in the muscularis mucosa of human EoE subjects $[15,31$, 32]. Specifically, tryptase-positive mast cells are elevated in the epithelium and smooth muscle, but connective tissue mast cells (chymase-tryptase double positive) are not elevated [15]. This suggests a potential functional interplay between tryptase-positive mast cells and the eosinophils. Mast cell accumulation remains elevated in animals that overexpress IL- 5 but lack eosinophils, demonstrating an eosinophil-independent IL-5-driven mast cell accumulation for esophageal mastocytosis [17]. Pediatric subjects treated with an anti-IL-5 antibody have a $50 \%$ reduction in eosinophil numbers, and similar decreases in esophageal eosinophilia are seen in adults $[25,33]$. Interestingly, pediatric subjects also have reductions in the numbers of mast cells [34]. This may be due to unappreciated direct effects of IL-5 on mast cells, but appears to also be a component of eosinophil-mediated mast cell survival. Eosinophils produce IL-9 in the pediatric esophagus, and mast cells and eosinophils are seen in couplets and clusters prior to anti-IL-5 therapy [34]. Following therapy, however, the numbers of IL-9-producing cells as well as the numbers of eosinophil-mast cell couplets are reduced [34]. This interplay between cellular subsets may have significant implications for the management of remodeling and its clinical consequences in human EoE.

TGF- $\beta 1$ is the common pathway in a number of fibrotic diseases [35]. Our lab and others have demonstrated increased levels of TGF- $\beta 1$ protein and mRNA in the biopsies of pediatric and adult EoE subjects $[12,18,36]$. Both eosinophils and mast cells are significant sources of TGF- $\beta 1$ in the EoE esophagus, and EoE epithelial cells also produce TGF- $\beta 1[12,15,36]$. TGF- $\beta 1$ expression has a number of effects including the promotion of profibrotic factors such as collagen I, and the direct transcription-dependent contraction of cultured esophageal smooth muscle cells [15]. Egg protein (ovalbumin)-induced murine EoE induces esophageal fibrosis which can be diminished in animals deficient for the $S \operatorname{mad} 3$ gene which is required for proper TGF- $\beta 1$ signals [Cho et al., submitted].

Food impactions are likely due in part to smooth muscle dysfunction. A recently described murine EoE model shows that basophils and thymic stromal lymphopoietin are necessary for the development of food impactions [37]. Treatment of EoE mice in this model system with a basophil-depleting or TSLP-blocking antibodies resolves the tendency to food impactions in mice [37].

Another component of esophageal remodeling is angiogenesis $[12,38]$. New blood vessels form fresh conduits for inflammatory cell infiltration into target tissues. In addition, blood vessels become activated in the presence of Th2 inflammation to express adhesion molecules that facilitate eosinophil adherence and transmigration through the vascular wall and into the tissue. In the case of EoE, pediatric subjects have increased vessels, increased vascular activation with VCAM-1, and increased proangiogenic factors such as VEGF and angiogenin [12, 38].

\section{Clinical Effects of Eosinophil-Associated Tissue \\ Remodeling}

The clinical consequences of eosinophil-associated remodeling can be severe. Heart failure can occur with endomyocardial fibrosis in HES and irreversible airway obstruction can occur in remodeled asthmatic subjects [1, 2]. In EoE, persistent eosinophilia is associated with tissue fibrosis, resulting in decreased esophageal compliance, increased esophageal stiffness, smaller esophageal diameter, increased smooth muscle mass with smooth muscle dysfunction, and ultimately dysphagia, food impactions, esophageal strictures, and a significantly decreased quality of life [7, 39-44].

There are obstacles to understanding the clinical implications of histological remodeling even in EoE where tissue is repeatedly obtained. Since only $40-60 \%$ of esophageal specimens have adequate LP for evaluation, there may be an intrinsic bias to the population that can be studied for remodeling in most studies. In addition, large studies that evaluate multiple remodeling features simultaneously and systematically are still pending. However, 
much has been learned in a relatively short time frame in this disease concerning structural consequences and clinical complications occurring due to remodeling.

Pediatric EoE is associated with fibrosis even at young ages $[12,13]$. However, perhaps due to the shorter untreated disease duration, strictures are not commonly seen and dilation is a rare requirement [7]. This is consistent with eosinophil-associated remodeling where fibrotic tissue changes occur over long periods of time [45]. Fifty-seven to $89 \%$ of children diagnosed with EoE have LP fibrosis on their diagnostic biopsy $[13,46]$, and at least $39 \%(n=16)$ of adult patients have LP fibrosis [45, 47]. A recent study demonstrated that up to $88 \%$ of EoE adults can have LP fibrosis [45]. In children, LP fibrosis and eosinophilia correlate closely with esophageal pallor and furrows on endoscopy [48]. Findings of LP fibrosis and eosinophilia also can correlate with symptoms of dysphagia and anorexia/early satiety in children [48].

During the disease course, the endoscopic features of EoE shift away from those that reflect inflammation, such as plaques, toward those such as concentric rings, narrowing, and strictures that reflect remodeling [45]. Using a technique known as 'EndoFLIP', Kwiatek et al. [39] demonstrated that esophageal rigidity is higher in adult EoE subjects. Although it seems intuitive that this would correspond to the degree of fibrosis, this has not been assessed yet. The least compliant esophagi are seen in those adults with strictures [39]. What is clear is that esophageal compliance is lower in those subjects who are prone to food impactions and/or dilations [49]. As such, esophageal distensibility measurements may provide a predictive index for food impactions [49]. While reported rates of strictures in children are $10 \%$ or less, stricture rates in adults range from 11 to $31 \%$ in cross-sectional studies, but can be as high as $72 \%$ when the EoE treatment is delayed $[7,45]$. Consistent with eosinophil-associated fibrosis, the risk and rate of strictures increases with increasing duration of diagnostic delay (based on the timing of symptom onset). While stricture rates in adults is $17.2 \%$ when the diagnostic delay is $0-2$ years, after more than 20 years $71 \%$ of subjects have strictured EoE [45]. Given this disease course, it may be of significant importance to intervene early and aggressively in those subjects who seem predisposed to a more fibrotic EoE disease phenotype.

Smooth muscle hypertrophy is evident in both children and adults using transesophageal ultrasound [10,11, 36]. Functional studies have demonstrated that the longitudinal and smooth muscle layers can become discoordinated and that dysphagia correlates in time with dysmotility $[50,51]$. As such, the clinical complaint of dys- phagia and the complication of food impaction are likely due to smooth muscle dysfunction. Children with EoE have increased eosinophil and mast cell infiltration into the smooth muscle bundles of the muscularis mucosa as compared with normal controls [15]. Case reports demonstrate that the deep smooth muscle bundles of the muscularis propria (not seen on routine biopsy specimens) are also infiltrated by eosinophils and mast cells in EoE [52]. Mice that lack mast cells have fewer proliferating smooth muscle cells and less smooth muscle area [14]. Both eosinophils and mast cells produce TGF- $\beta 1$, and TGF- $\beta 1$ can cause transcription-dependent esophageal smooth muscle cell contraction in vitro [15]. As such, it is likely that inflammation is a major driving force for smooth muscle abnormalities in EoE.

\section{Reversibility of Esophageal Remodeling}

One prominent issue in EoE is the potential reversibility of remodeling. The answer to this question may be different in children and adults and dependent on the duration and type of therapy. Our lab has demonstrated that in pediatric EoE subjects there is a correlation between the response to therapy that is seen in the epithelium and the response to therapy that is seen in the subepithelial space [20]. Following treatment with 3 months of viscous topical budesonide, children who are considered 'responders' by posttherapy epithelial eosinophil counts of $\leq 7$ eosinophils per high-power field had decreases in their LP fibrosis scores [20]. In addition, there was remission in the numbers of LP eosinophils and TGF- $\beta 1$ producing and $\mathrm{pSmad} 2 / 3$-positive cells in the LP. In contrast, children who had persistent eosinophilic inflammation in the epithelium had persistently elevated or progressively worsening fibrosis scores and continued LP inflammation with eosinophils as well as TGF- $\beta 1$ and pSmad2/3positive cells [20].

Dietary interventions can also decrease esophageal remodeling in EoE, both in isolation or in addition to topical corticosteroid therapy. Eighteen percent of children treated with elimination diets had decreases in their fibrosis scores (as opposed to $56 \%$ treated with topical swallowed fluticasone) [21]. Pediatric EoE subjects treated with combination therapy of elimination diet in addition to topical fluticasone also have reductions in fibrosis following treatment [22]. Whether there are differences in controlling fibrosis with an elimination diet as opposed to topical corticosteroids in large cohorts of subjects remains to be evaluated.

Studies in adults have given more complex results in terms of remodeling response to therapy $[10,16,36]$. In one study in which adults were treated for 1 year with top-
18 
ical fluticasone in doses and formulation adequate to treat epithelial eosinophilia, many had persistent LP fibrosis following therapy and the decreases in fibrosis scores were not statistically significant [16]. By contrast, in a 15-day study of topical budesonide, adult subjects had improvements in LP fibrosis and epithelial TGF- $\beta 1$ expression [36]. When treated with a decreased dose of topical budesonide for an extended period of time (52 weeks), these same adults continued to have lower LP fibrosis scores than placebo-treated subjects, but had increased scores as compared with their initial scores when on higher-dose therapy [10]. In addition, although transmural esophageal thickness was improved, it did not resolve with long-term therapy [10]. In adult subjects treated with budesonide, the overall esophageal diameter was not improved. However, when a subanalysis was done on those subjects who began with narrowed esophagus, there was an improvement in esophageal diameter following therapy [53]. These observations are important and support the conclusions that (1) pediatric subjects likely have a disease that can be modified in terms of LP fibrosis if they are responsive to therapy, (2) adult subjects likely have fibrosis that is more difficult to reverse, (3) while the subepithelial response in children aligns with the epithelial response to therapy, in adults there can be discordance between the epithelial and subepithelial response to therapy, and (4) there is heterogeneity in the ability to control subepithelial fibrosis among both pediatric and adult EoE subjects. These data are intriguing as they suggest that LP inflammation can drive remodeling independent of epithelial inflammation and/or that fibrosis becomes independent of inflammatory signals, especially in adult EoE subjects.

Biologic agents have also been assessed in adults for remodeling control in EoE. Anti-IL-5 used in adult patients at escalating doses decreased, but did not normalize esophageal epithelial eosinophilia [25]. Epithelial cell expression of TGF- $\beta 1$ was decreased following mepolizumab treatment for adult EoE, and basement membrane tenascin $\mathrm{C}$ was also diminished [25]. Unlike pediatric subjects, there was no decrease in epithelial mast cells and IL-9 has not been evaluated in adult EoE. Although other biologic agents such as anti-IL-13 may be of utility in EoE, the results of these clinical trials have yet to be published.

\section{Conclusions}

Much has been learned from EoE concerning eosinophil-related esophageal remodeling. Pediatric and adult subjects appear to differ on a number of points when it

comes to remodeling. This may be due to the duration of untreated disease, genetic and/or environmental factors, the type and/or duration of therapy, the age of the subject when treatment was started, or combinations of all of these factors. Since disease duration, especially untreated disease duration, increases the rate of strictures, it is important to minimize the diagnostic delay and to treat EoE with anti-inflammatory agents in order to potentially alter the natural history to complications such as strictures. In children, where epithelial inflammatory control appears to align with LP fibrosis control, there may be a unique opportunity to control remodeling due to this concordance. In addition, there may be an epithelial molecular signature in pediatric EoE that correlates or reflects LP remodeling. In reality, the use of medical and dietary interventions masks the true natural history of EoE, but is required in order to effectively manage the patient's disease and quality of life.

Despite their differences, children and adult EoE subjects also have a number of similarities. The pathogenesis is similar with increases in IL-5, IL-13, and TGF- $\beta 1$, at least in a subset of subjects. What is clear is that EoE offers a unique and impactful ability for researchers and clinicians to understand more about eosinophil-associated esophageal remodeling.

\section{Acknowledgements}

Funding from NIH/NIAID, AI092135, ART/APFED, DOD FA100044, a Department of Defense grant for the genetics of food allergy, and the AAAAI/APFED Hope Pilot grant.

\section{Disclosure Statement}

Consulting agreements: Receptos Pharmaceuticals, Regeneron Pharmaceuticals. Patents/Royalties: Meritage Pharma for co-inventor on UCSD-patented oral viscous budesonide.

\section{References}

Dig Dis 2014;32:15-21

DOI: $10.1159 / 000357004$
1 Podjasek JC, Butterfield JH: Mortality in hypereosinophilic syndrome: 19 years of experience at Mayo Clinic with a review of the literature. Leuk Res 2013;37:392-395.

2 Broide DH: Immunologic and inflammatory mechanisms that drive asthma progression to remodeling. J Allergy Clin Immunol 2008; 121:560-570, quiz 571-572.

3 Malmström K, Pelkonen AS, Mäkelä MJ: Remodeling, inflammation and airway responsiveness in early childhood asthma. Curr Opin Allergy Clin Immunol 2013;13:203210. 
4 Klion A: Hypereosinophilic syndrome: current approach to diagnosis and treatment. Annu Rev Med 2009;60:293-306.

5 Aceves SS, Ackerman SJ: Relationships between eosinophilic inflammation, tissue remodeling, and fibrosis in eosinophilic esophagitis. Immunol Allergy Clin North Am 2009; 29:197-211, xiii-xiv.

6 Aceves SS: Tissue remodeling in patients with eosinophilic esophagitis: what lies beneath the surface? J Allergy Clin Immunol 2011;128: 1047-1049.

7 Liacouras CA, Furuta GT, Hirano I, Atkins D, Attwood SE, Bonis PA, Burks AW, Chehade M, Collins MH, Dellon ES, et al: Eosinophilic esophagitis: updated consensus recommendations for children and adults. J Allergy Clin Immunol 2011;128:3-20.e26, quiz 21-22.

$\checkmark 8$ Cheng E, Souza RF, Spechler SJ: Tissue remodeling in eosinophilic esophagitis. Am J Physiol Gastrointest Liver Physiol 2012; 303:G1175-G1187.

-9 Straumann A, Spichtin HP, Grize L, Bucher KA, Beglinger C, Simon HU: Natural history of primary eosinophilic esophagitis: a followup of 30 adult patients for up to 11.5 years. Gastroenterology 2003;125:1660-1669.

10 Straumann A, Conus S, Degen L, Frei C, Bussmann C, Beglinger C, Schoepfer A, Simon HU: Long-term budesonide maintenance treatment is partially effective for patients with eosinophilic esophagitis. Clin Gastroenterol Hepatol 2011;9:400-409.e1.

-11 Fox VL, Nurko S, Teitelbaum JE, Badizadegan K, Furuta GT: High-resolution EUS in children with eosinophilic 'allergic' esophagitis. Gastrointest Endosc 2003;57:30-36.

-12 Aceves SS, Newbury RO, Dohil R, Bastian JF, Broide DH: Esophageal remodeling in pediatric eosinophilic esophagitis. J Allergy Clin Immunol 2007;119:206-212.

13 Chehade M, Sampson HA, Morotti RA, Magid MS: Esophageal subepithelial fibrosis in children with eosinophilic esophagitis. J Pediatr Gastroenterol Nutr 2007;45:319-328.

14 Niranjan R, Mavi P, Rayapudi M, Dynda S, Mishra A: Pathogenic role of mast cells in experimental eosinophilic esophagitis. Am J Physiol Gastrointest Liver Physiol 2013; 304:G1087-G1094.

15 Aceves SS, Chen D, Newbury RO, Dohil R, Bastian JF, Broide DH: Mast cells infiltrate the esophageal smooth muscle in patients with eosinophilic esophagitis, express TGF- $\beta 1$, and increase esophageal smooth muscle contraction. J Allergy Clin Immunol 2010;126: 1198-1204.e4.

16 Lucendo AJ, Arias A, De Rezende LC, YagueCompadre JL, Mota-Huertas T, GonzalezCastillo S, Cuesta RA, Tenias JM, Bellon T: Subepithelial collagen deposition, profibrogenic cytokine gene expression, and changes after prolonged fluticasone propionate treatment in adult eosinophilic esophagitis: a prospective study. J Allergy Clin Immunol 2011; 128:1037-1046.
17 Mavi P, Rajavelu P, Rayapudi M, Paul RJ, Mishra A: Esophageal functional impairments in experimental eosinophilic esophagitis. Am J Physiol Gastrointest Liver Physiol 2012;302:G1347-G1355.

18 Mishra A, Wang M, Pemmaraju VR, Collins MH, Fulkerson PC, Abonia JP, Blanchard C, Putnam PE, Rothenberg ME: Esophageal remodeling develops as a consequence of tissue specific IL-5-induced eosinophilia. Gastroenterology 2008;134:204-214.

19 Kagalwalla AF, Akhtar N, Woodruff SA, Rea BA, Masterson JC, Mukkada V, Parashette KR, Du J, Fillon S, Protheroe CA, et al: Eosinophilic esophagitis: epithelial mesenchymal transition contributes to esophageal remodeling and reverses with treatment. J Allergy Clin Immunol 2012;129:1387-1396.e7.

-20 Aceves SS, Newbury RO, Chen D, Mueller J, Dohil R, Hoffman H, Bastian JF, Broide DH: Resolution of remodeling in eosinophilic esophagitis correlates with epithelial response to topical corticosteroids. Allergy 2010;65: 109-116.

21 Lieberman JA, Morotti RA, Konstantinou GN, Yershov O, Chehade M: Dietary therapy can reverse esophageal subepithelial fibrosis in patients with eosinophilic esophagitis: a historical cohort. Allergy 2012;67:1299-1307.

22 Abu-Sultaneh SM, Durst P, Maynard V, Elitsur Y: Fluticasone and food allergen elimination reverse sub-epithelial fibrosis in children with eosinophilic esophagitis. Dig Dis Sci 2011;56:97-102.

23 Assa’ad AH, Putnam PE, Collins MH, Akers RM, Jameson SC, Kirby CL, Buckmeier BK, Bullock JZ, Collier AR, Konikoff MR, et al: Pediatric patients with eosinophilic esophagitis: an 8-year follow-up. J Allergy Clin Immunol 2007;119:731-738.

24 Mulder DJ, Pacheco I, Hurlbut DJ, Mak N, Furuta GT, MacLeod RJ, Justinich CJ: FGF9induced proliferative response to eosinophilic inflammation in oesophagitis. Gut 2009;58: 166-173.

25 Straumann A, Conus S, Grzonka P, Kita H, Kephart G, Bussmann C, Beglinger C, Smith DA, Patel J, Byrne M, et al: Anti-interleukin-5 antibody treatment (mepolizumab) in active eosinophilic oesophagitis: a randomised, placebo-controlled, double-blind trial. Gut 2010; 59:21-30.

26 Blanchard C, Stucke EM, Burwinkel K, Caldwell JM, Collins MH, Ahrens A, Buckmeier BK, Jameson SC, Greenberg A, Kaul A, et al: Coordinate interaction between IL-13 and epithelial differentiation cluster genes in eosinophilic esophagitis. J Immunol 2010; 184:4033-4041.

27 Blanchard C, Mingler MK, Vicario M, Abonia JP, Wu YY, Lu TX, Collins MH, Putnam PE, Wells SI, Rothenberg ME: IL-13 involvement in eosinophilic esophagitis: transcriptome analysis and reversibility with glucocorticoids. J Allergy Clin Immunol 2007;120: 1292-1300.
8 Zuo L, Fulkerson PC, Finkelman FD, Mingler M, Fischetti CA, Blanchard C, Rothenberg ME: IL-13 induces esophageal remodeling and gene expression by an eosinophil-independent, IL-13R alpha 2-inhibited pathway. J Immunol 2010;185:660-669.

29 Blanchard C, Mingler MK, McBride M, Putnam $\mathrm{PE}$, Collins $\mathrm{MH}$, Chang $\mathrm{G}$, Stringer $\mathrm{K}$, Abonia JP, Molkentin JD, Rothenberg ME: Periostin facilitates eosinophil tissue infiltration in allergic lung and esophageal responses. Mucosal Immunol 2008;1:289-296.

30 Blanchard C, Mishra A, Saito-Akei H, Monk P, Anderson I, Rothenberg ME: Inhibition of human interleukin-13-induced respiratory and oesophageal inflammation by anti-human-interleukin-13 antibody (CAT-354). Clin Exp Allergy 2005;35:1096-1103.

- 31 Abonia JP, Blanchard C, Butz BB, Rainey HF, Collins MH, Stringer K, Putnam PE, Rothenberg ME: Involvement of mast cells in eosinophilic esophagitis. J Allergy Clin Immunol 2010;126:140-149.

- 32 Dellon ES, Chen X, Miller CR, Fritchie KJ, Rubinas TC, Woosley JT, Shaheen NJ: Tryptase staining of mast cells may differentiate eosinophilic esophagitis from gastroesophageal reflux disease. Am J Gastroenterol 2011;106: 264-271.

33 Assa'ad AH, Gupta SK, Collins MH, Thomson M, Heath AT, Smith DA, Perschy TL, Jurgensen $\mathrm{CH}$, Ortega HG, Aceves SS: An antibody against IL-5 reduces numbers of esophageal intraepithelial eosinophils in children with eosinophilic esophagitis. Gastroenterology 2011;141:1593-1604.

34 Otani IM, Anilkumar AA, Newbury RO, Bhagat M, Beppu LY, Dohil R, Broide DH, Aceves SS: Anti-IL-5 therapy reduces mast cell and IL-9 cell numbers in pediatric patients with eosinophilic esophagitis. J Allergy Clin Immunol 2013;131:1576-1582.

35 Akhurst RJ, Hata A: Targeting the TGF $\beta$ signalling pathway in disease. Nat Rev Drug Discov 2012;11:790-811.

36 Straumann A, Conus S, Degen L, Felder S, Kummer M, Engel H, Bussmann C, Beglinger C, Schoepfer A, Simon HU: Budesonide is effective in adolescent and adult patients with active eosinophilic esophagitis. Gastroenterology 2010;139:1526-1537.

- 37 Noti M, Wojno ED, Kim BS, Siracusa MC, Giacomin PR, Nair MG, Benitez AJ, Ruymann KR, Muir AB, Hill DA, et al: Thymic stromal lymphopoietin-elicited basophil responses promote eosinophilic esophagitis. Nat Med 2013;19:1005-1013.

- 38 Persad R, Huynh HQ, Hao L, Ha JR, Sergi C, Srivastava R, Persad S: Angiogenic remodeling in pediatric EoE is associated with increased levels of VEGF-A, angiogenin, IL-8, and activation of the TNF $\alpha-N F \kappa B$ pathway. J Pediatr Gastroenterol Nutr 2012;55:251-260.

39 Kwiatek MA, Hirano I, Kahrilas PJ, Rothe J, Luger D, Pandolfino JE: Mechanical properties of the esophagus in eosinophilic esophagitis. Gastroenterology 2011;140:82-90. 
40 Straumann A, Bussmann C, Zuber M, Vannini S, Simon HU, Schoepfer A: Eosinophilic esophagitis: analysis of food impaction and perforation in 251 adolescent and adult patients. Clin Gastroenterol Hepatol 2008;6: 598-600.

-41 Franciosi JP, Hommel KA, Bendo CB, King EC, Collins MH, Eby MD, Marsolo K, Abonia JP, von Tiehl KF, Putnam PE, et al: PedsQL eosinophilic esophagitis module: feasibility, reliability, and validity. J Pediatr Gastroenterol Nutr 2013;57:57-66.

42 Franciosi JP, Hommel KA, Greenberg AB, Debrosse CW, Greenler AJ, Abonia JP, Rothenberg ME, Varni JW: Development of the Pediatric Quality of Life Inventory ${ }^{\mathrm{TM}}$ Eosinophilic Esophagitis module items: qualitative methods. BMC Gastroenterol 2012;12: 135.

-43 Gonsalves N, Yang GY, Doerfler B, Ritz S, Ditto AM, Hirano I: Elimination diet effectively treats eosinophilic esophagitis in adults; food reintroduction identifies causative factors. Gastroenterology 2012;142:1451-1459. e1.
44 Harris RF, Menard-Katcher C, Atkins D, Furuta GT, Klinnert MD: Psychosocial dysfunction in children and adolescents with eosinophilic esophagitis. J Pediatr Gastroenterol Nutr 2013;57:500-505.

45 Schoepfer AM, Safroneeva E, Bussmann C, Kuchen T, Portmann S, Simon HU, Straumann A: Delay in diagnosis of eosinophilic esophagitis increases risk for stricture formation, in a time-dependent manner. Gastroenterology 2013, E-pub ahead of print.

46 Li-Kim-Moy JP, Tobias V, Day AS, Leach S, Lemberg DA: Esophageal subepithelial fibrosis and hyalinization are features of eosinophilic esophagitis. J Pediatr Gastroenterol Nutr 2011;52:147-153.

47 Parfitt JR, Gregor JC, Suskin NG, Jawa HA, Driman DK: Eosinophilic esophagitis in adults: distinguishing features from gastroesophageal reflux disease: a study of $41 \mathrm{pa}-$ tients. Mod Pathol 2006;19:90-96.

48 Aceves SS, Newbury RO, Dohil MA, Bastian JF, Dohil R: A symptom scoring tool for identifying pediatric patients with eosinophilic esophagitis and correlating symptoms with inflammation. Ann Allergy Asthma Immunol 2009;103:401-406.
49 Nicodeme F, Hirano I, Chen J, Robinson K, Lin Z, Xiao Y, Gonsalves N, Kwasny MJ, Kahrilas PJ, Pandolfino JE: Esophageal distensibility as a measure of disease severity in patients with eosinophilic esophagitis. Clin Gastroenterol Hepatol 2013;11:1101-1107.

50 Korsapati H, Babaei A, Bhargava V, Dohil R, Quin A, Mittal RK: Dysfunction of the longitudinal muscles of the oesophagus in eosinophilic oesophagitis. Gut 2009;58:1056-1062.

-51 Nurko S, Rosen R, Furuta GT: Esophageal dysmotility in children with eosinophilic esophagitis: a study using prolonged esophageal manometry. Am J Gastroenterol 2009; 104:3050-3057.

52 Nicholson AG, Li D, Pastorino U, Goldstraw P, Jeffery PK: Full thickness eosinophilia in oesophageal leiomyomatosis and idiopathic eosinophilic oesophagitis. A common allergic inflammatory profile? J Pathol 1997;183:233236.

53 Lee J, Huprich J, Kujath C, Ravi K, Enders F, Smyrk TC, Katzka DA, Talley NJ, Alexander JA: Esophageal diameter is decreased in some patients with eosinophilic esophagitis and might increase with topical corticosteroid therapy. Clin Gastroenterol Hepatol 2012;10:481-486. 